\title{
Pakistan's National Surgical, Obstetric, and Anesthesia Plan: an adapted model for a devolved federal-provincial health system
}

\author{
Irum Fatima, MPH (1) - Haitham Shoman, MPH • Alexander W. Peters, MPH • Lubna Samad, FCPS • \\ Sania Nishtar, PhD
}

Received: 17 February 2020/Revised: 10 April 2020/Accepted: 10 April 2020/Published online: 14 May 2020

(C) Canadian Anesthesiologists' Society 2020

Access to safe surgical care has been acknowledged as a major global and public health concern in recent years. In 2010, 16.9 million people died from conditions requiring surgical care; this exceeded the mortality caused by HIV/ AIDS, tuberculosis, and malaria combined during the same period. ${ }^{1}$ It is estimated that 77 million disability-adjusted life years could be averted through access to basic surgical care. $^{2}$ In Pakistan, acute surgical illnesses result in 187 deaths per 100,000 of population compared with 164 deaths per 100,000 of population caused by infectious diseases. ${ }^{3}$ In 2015, The Lancet Commission on Global Surgery (LCoGS) launched its report "Global Surgery 2030" and proposed the National Surgical, Obstetric and Anesthesia Plan (NSOAP) approach as a guide to help committed countries frame their surgical care strategies. ${ }^{2}$ In Pakistan, a coordinated, comprehensive, and tailored approach using this framework is required to meet the country's need for optimizing surgical care delivery.

I. Fatima, MPH $(\bowtie) \cdot$ L. Samad, FCPS

Global Health Directorate, Indus Health Network, Karachi, Pakistan

e-mail: irum.fatima@ghd.ihn.org.pk

H. Shoman, MPH

Program in Global Surgery and Social Change, Harvard Medical

School, Boston, MA, USA

A. W. Peters, MPH

Program in Global Surgery and Social Change, Harvard Medical

School, Boston, MA, USA

Department of Surgery, Weill Cornell Medical College, New York, NY, USA

S. Nishtar, PhD

HeartFile, Islamabad, Pakistan
The LCoGS framework builds upon six interdependent domains that provide a platform for NSOAP development: infrastructure, workforce, service delivery, financing, information management, and governance. ${ }^{4}$ The LCoGS also proposed six indicators to measure the baseline and monitor the progress of surgical care in a given country. ${ }^{2}$ They include: 1) two-hour access to timely essential surgery; 2) surgical, anesthesia, and obstetrics density per 100,000 of population; 3) surgical procedures volume per 100,000 of population; 4) perioperative mortality rates; 5) risk of impoverishing expenditure; and 6) risk of catastrophic expenditure. These indicators have been included in the World Bank Groups' World Development Indicators repository, ${ }^{5}$ thus placing the onus on member countries to focus on surgical care.

\section{Pakistan's health system}

Pakistan's health system has faced significant challenges and has fallen short of achieving the United Nations' Millennium Development Goals (MDGs). Specifically, the targets for reduction of child mortality (MDG-4) and improving maternal health (MDG-5) were not achieved. Going forward, achieving the health-related United Nations' sustainable development goal (SDG)-3 to "ensure healthy lives and promote well-being for all at all ages" will require an interdisciplinary approach. We must improve existing preventive and primary health interventions, and to achieve this goal we must renew our focus on strengthening surgical care to provide interventions for common problems like congenital malformations and complicated childbirths. In Pakistan, access to emergency and essential surgical services remains severely compromised, so there is potential for 
an improvement in surgical care to significantly contribute to achieving SDG-3 targets. ${ }^{3}$

Pakistan is a federation with a population of over 207 million. It has a capital territory, Islamabad, and four provinces, each with a provincial capital. Two semiautonomous regions, Gilgit Baltistan and Azad Jummu and Kashmir, are directly supervised by the federal capital. Since 1947, the federal government had control over the provinces for all legislative, administrative, and financial matters in all ministries including health. ${ }^{6}$ In 2010, when the $18^{\text {th }}$ Amendment to the Constitution of Pakistan mandated provincial autonomy for all portfolios except for key national functions such as defense and foreign affairs. As a direct consequence of this Amendment, the Federal Ministry of Health (MoH) was abolished in 2011, making Pakistan possibly the only federation in the world at that time without a federal ministry or coordinating body for healthcare. Financial autonomy was granted to provinces, thus providing the opportunity to restructure health services in accordance with regional priorities, with the understanding that provincial governments would be better suited to allocate resources and finances to achieve better health outcomes.

Prior to this devolution, the $\mathrm{MoH}$ was responsible for the provision of basic packages of standardized services, including improving human resources for healthcare, gathering and using health information to guide decisionmaking, and adopting emerging technologies. ${ }^{7}$ After devolution, however, the MoH's responsibilities, including planning and resource allocation for provision of preventive and curative healthcare, were reassigned and devolved to provincial Departments of Health (DoH). The provincial DoHs were granted the responsibility to frame laws, rules, and regulations; develop standards for quality control of drugs and of healthcare services; and prescribe standards for medical education and the training of doctors, nurses, and paramedics. To varying extents, the provinces were not prepared for this transition ${ }^{6}$ since historically their focus was implementation and not policy development or regulation. Once the devolution process was underway, there was a growing realization that a federal entity was required to develop policy guidelines at a national level, oversee health regulation, carry out national disease surveillance, integrate health information for decision-making, enforce drug laws and regulations, coordinate with international agencies and donors, and organize preventive and population level interventions. To this end, the Ministry of National Health Services, Regulation and Coordination (M/oNHSR\&C) was established. In addition to the above functions, the M/oNHSR\&C is directly responsible for healthcare delivery in the Islamabad Capital Territory.
National Health Vision (NHV) 2016-2025

Pakistan's NHV 2016-2025 was launched by the M/ oNHSR\&C, and gives a strategic direction and a road map to the healthcare delivery system agreed upon by the provincial health departments and governments. It promises better health for all and aims to deliver healthcare through a "responsive" and "resilient" healthcare system. ${ }^{8}$ Nevertheless, the NHV does not recognize surgical diseases as a distinct component of the health needs of the population of Pakistan and fails to highlight challenges specific to surgical care delivery. Consequently, the document is unable to provide strategic direction for promoting and strengthening essential surgical care. This is a reflection of the overall global situation, where surgery was not considered to be a part of the global health dialogue until very recently.

\section{National surgical planning in Pakistan}

It is encouraging to note that Pakistan is a signatory to the World Health Assembly (WHA) Resolution 68.15 "Strengthening emergency and essential surgical care and anesthesia as an essential component of universal health coverage". The WHA secretariat reiterates that surgical care is an integral part of primary healthcare and more than 2,000 million people are unable to access even basic surgical care. This resolution clearly calls on the member states to raise awareness, ensure political commitment, and address gaps to prioritize surgical care at all levels of the health system. It recognizes access to safe surgical and anesthesia care as a fundamental human right and an essential component of universal healthcare.$^{10}$ It highlights the importance of trained surgical workforce and infrastructure to provide quality care. ${ }^{9}$ During the $71^{\text {st }}$ WHA in Geneva, the Pakistan delegation had the opportunity to meet with key international stakeholders representing the Essential and Emergency Surgical Program at the World Health Organization (WHO), Program in Global Surgery and Social Change (PGSSC) at Harvard Medical School, World Federation of Societies of Anaesthesiologists (WFSA), and the Indus Health Network (IHN) in Pakistan, who were able to make a strong case for the dire need to address Pakistan's severely compromised surgical care delivery. It was proposed by these representatives that the NSOAP framework could be used to guide this process. Following this meeting, the M/ oNHSR\&C has taken positive steps by developing a "National Vision for Surgical Care 2025 (NVSC2025)" in partnership with the IHN, a charitable national network providing healthcare at primary, secondary, and tertiary levels. Funded through philanthropic donations as well as 
through public-private partnerships with federal and provincial governments, surgical care has been a focus for IHN because the high, one-time cost of surgical procedures is prohibitive for most of the population in Pakistan. Technical support for development and dissemination of NVSC2025 has been provided by WHO and PGSSC.

Pakistan's federal-provincial model has driven the NSOAP process to be adapted and customized in line with the country's health governance structure and operational dynamics. The MoNHSR\&C and IHN jointly hosted a two-day National Stakeholders' Conference in November 2018 in Islamabad that was attended by representatives from public and private healthcare sectors; academia, relevant professional bodies including societies of surgery, anesthesia, obstetrics and gynecology, pediatric surgery, and orthopedics; regulatory bodies including the College of Physicians and Surgeons of Pakistan and the Pakistan Medical and Dental Council; and key international stakeholders including WHO, PGSSC, WFSA, Department of International Development, United Nations International Children's Emergency Fund, Kreditanstalt für Wiederaufbau, and the International Committee of the Red Cross. Representatives from provincial planning departments participated in the workshop and committed to include provision of safe surgical care as a priority agenda during the development of provincial annual strategic plans. This was the first time in Pakistan that representatives of surgical and anesthesia communities discussed the challenges and solutions for delivering surgical care within a policy framework.
From the very start, focused efforts were made to include anesthetists, obstetricians and gynecologists, and pediatric surgeons in the discussions, since they represent critically important, but often overlooked, constituencies. During the conference, all group discussions were structured around the six LCoGS domains and the outcome of these discussions formed the basis of the consensus statement. This statement provides a road map for initiating a process that would create an addendum document to the NHV for 2025 to fill the gap in recognizing and addressing challenges in surgical care delivery in the country. An initial draft of the NVSC2025 document was prepared with the collaborative efforts of the M/oNHSR\&C, IHN, and PGSSC, following which consultative workshops were held in each provincial capital in March 2019 (Figure). Participants at these workshops included stakeholders from provincial DoH, planning and development, as well as general surgeons, gynecologists and obstetricians, anesthetists, and orthopedic surgeons from leading private and public sector facilities. Discussions focused around the six NSOAP domains identified province-specific gaps and challenges, specifically in surgical infrastructure, SOA workforce availability, and service delivery. Within each province, marked variations between urban and rural populations were highlighted, and possible strategies to address this inequity were proposed. These discussions were collated and added to the NVSC2025 document, which was finally presented to the M/oNHSR\&C for approval and dissemination.

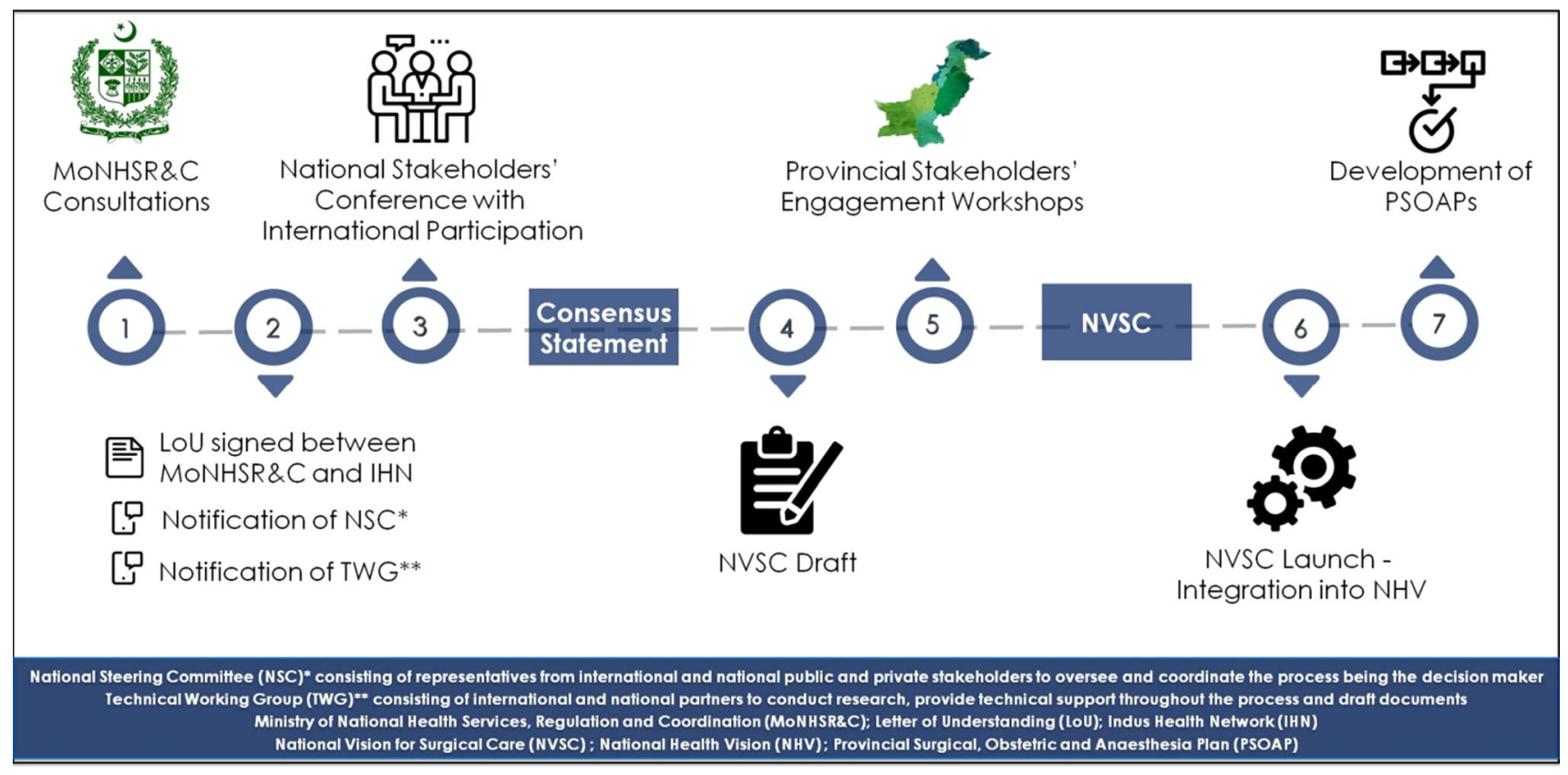

Figure Roadmap towards Pakistan's National Vision for Surgical Care 2016-2025 @ Syeda Mahnoor Rizvi 
The provincial stakeholders' meetings have set the stage for each province to recognize the importance of strengthening surgical platforms and identify provincial champions who will in turn develop provincial surgical, anesthesia, and obstetric plans (PSOAPs) catered to the needs of each region. The NSOAP template will be used as a guiding framework for these provincial plans, and its inherent flexibility allows the approach to be adapted to diverse settings. In line with the coordinating function of the M/oNHSR\&C, NVSC2025 will be coordinated centrally, while the PSOAPs will allow customized strategy and implementation at the provincial level.

The NSOAP framework has already been used to develop national surgical plans in several low- and middle-income countries. To date, these are African countries: five countries have launched an NSOAP, six are in the process of drafting their surgical plans, and twelve have shown interest in following this path. Pakistan is the pioneer for this process in Asia, where resources are intrinsically different from the African context. Moreover, with a population of over 207 million, ${ }^{11}$ Pakistan is twice as populous as the biggest African country to have undertaken this process. An estimated 35\% of Pakistan's population is below the age of $15 \mathrm{yr}$. This is a particularly vulnerable subset because of the scarcity of trained surgeons, anesthetists, neonatologists, and ancillary staff that are essential to provide comprehensive neonatal and pediatric surgical care. ${ }^{12}$ It is a testament to the inherent adaptability of the NSOAP approach that it is applicable in such diverse settings.

This policy and implementation initiative has the potential to save lives, prevent disabilities, avert catastrophic expenditure, and promote the country's economic growth by reducing morbidity and mortality. Pakistan is well poised to pioneer a comprehensive surgical strengthening strategy that is relevant to its national and local needs. Moreover, this has the potential to serve as a model for other countries with similar demographic and resource dynamics. ${ }^{13}$ Pakistan's surgical strategy will contribute significantly towards universal health coverage and hence help achieve SDG-3 with spillover effects on other SDGs. ${ }^{14}$

\section{Conclusion}

The NVSC2025 is well adapted to Pakistan's devolved model of provincial autonomy in planning and implementation. The development of PSOAPs customized to local needs and demands has the potential to provide an effective approach to addressing surgical needs in a large population. This model presents a possible approach for other countries facing similar governance and population challenges. It is hoped that the Pakistan experience will be relevant and of interest to policy makers, care providers, and the broader global health community, and add to the growing momentum for structured surgical care delivery worldwide.

Author contributions Irum Fatima and Haitham Shoman contributed to all aspects of this manuscript, including study concept and design, literature review, manuscript writing, and submission. Alexander W. Peters helped with the literature review and policy implementation. Lubna Samad and Sania Nishtar developed and implemented the policy intervention. Lubna Samad also reviewed and edited the manuscript.

Acknowledgements The authors would like to extend their gratitude to Dr. Nabeel Ashraf and Dr. Dominique Vervoort who have been extremely supportive in the data collection and situational analysis phase of this project that have prompted the authors to write this editorial.

\section{Disclosures None.}

Funding statement None.

Editorial responsibility This submission was handled by Dr. Hilary P. Grocott, Editor-in-Chief, Canadian Journal of Anesthesia.

\section{References}

1. Ologunde R, Maruthappu M, Shanmugarajah K, Shalhoub J. Surgical care in low and middle-income countries: burden and barriers. Int J Surg 2014; 12: 858-63.

2. Meara JG, Leather AJ, Hagander L, et al. Global Surgery 2030: evidence and solutions for achieving health, welfare, and economic development. Lancet 2015; 386: 569-624.

3. Zafar SN, McQueen KA. Surgery, public health, and Pakistan. World J Surg 2011; 35: 2625-34.

4. Citron I, Sonderman K, Subi L, Meara JG. Making a case for national surgery, obstetric, and anesthesia plans. Can J Anesth 2019; 66: 263-71.

5. The World Bank. World Development Indicators. Available from URL: $\quad$ http://datatopics.worldbank.org/world-developmentindicators/ (accessed April 2020).

6. Nishtar S. Health and the 18th Amendment. Retaining national functions in devolution. Available from URL: http://www. heartfile.org/pdf/HEALTH_18AM_FINAL.pdf (accessed April 2020).

7. Government of Pakistan; Ministry of Health. National Health Policy 2009. Available from URL: https://www.uhc2030.org/ fileadmin/uploads/ihp/Documents/Country_Pages/Pakistan/ PakistanHealthPolicy2010-2015.pdf (accessed April 2020).

8. World Health Organization. National Health Vision, Pakistan 2016-2025. Available from URL: http://www. nationalplanningcycles.org/sites/default/files/planning_cycle_ repository/pakistan/national_health_vision_2016-25_30-08-2016. pdf (accessed April 2020).

9. Sixty-Eighth World Health Assembly. WHA68.15 1 Strengthening emergency and essential surgical care and anaesthesia as a component of universal health coverage. Geneva, Sixty Eighth 
World Health Assembly; Agenda Item 17.1; 2015. Available from URL: http://apps.who.int/gb/ebwha/pdf_files/WHA68/A68_ R15-en.pdf (accessed April 2020).

10. National Surgical, Obstetrics, and Anesthesia Planning Conference for World Health Organization Regional Officers and High-Level Authorities. 2019 Dubai. Available from URL: https://www.pgssc.org/2019-national-surgical-planning (accessed April 2020).

11. Pakistan Bureau of Statistics. Population Census. Available from URL: http://www.pbs.gov.pk/content/population-census (accessed April 2020).
12. Siddiqui S, Vervoort D, Peters AW, et al. Closing the gap of children's surgery in Pakistan. World Jnl Ped Surgery 2019. https://doi.org/10.1136/wjps-2018-000027.

13. Knowlton LM, Banguti P, Chackungal S, et al. A geospatial evaluation of timely access to surgical care in seven countries. Bull World Heal Organ 2017; 95: 437-44.

14. Roa L, Jumbam DT, Makasa E, Meara JG. Global surgery and the sustainable development goals. Br J Surg 2019; 106: e44-52.

Publisher's Note Springer Nature remains neutral with regard to jurisdictional claims in published maps and institutional affiliations. 